\title{
Automated 3D Block Preparation Procedure for Focused Ion Beam 3D Analyses
}

\author{
X. L. Zhong ${ }^{1}$, P.J Withers ${ }^{1}$, X Zhang ${ }^{1}$, S.B. Lyon ${ }^{1}$, T.L. Burnett ${ }^{1}$, X. Zhou ${ }^{1}$ and M.G. Burke ${ }^{1}$ \\ ${ }^{1}$ School of Materials, University of Manchester, United Kingdom.
}

Serial Section Dual Beam Focused Ion Beam Scanning Electron Microscopy (FIB-SEM) imaging has become increasingly important for three dimensional (3D) analyses providing chemical (EDX), crystallographic (EBSD) and morphological information. Recently available dual-beam $\mathrm{Xe}^{+}$plasma focused ion beam has expanded the window for materials 3D characterization [1]. The 3D analysis volume can be 1000 times larger than conventional $\mathrm{Ga}+$ focused ion beam. However, prior to automatic milling slices for analysis, the 3D block preparation often takes a large amount of time and manpower. We propose a procedure that enables 3D block preparation with minimal human intervention. This automated procedure is of widespread applicability for $3 \mathrm{D}$ analysis using conventional $\mathrm{Ga}^{+} \mathrm{FIB}$ or Plasma Xe ${ }^{+}$FIB.

A composite polymer coating (paint) used for the corrosion protection of steel has been studied [2]. Due to the severe difference in hardness difference between the hard pigments and the soft polymer matrix on top of steel, it is a challenging sample for 3D imaging by ultramicrotomy. FIB has been used by other researchers to reveal the pigment distribution but it is limited the examination of a statistically insufficient number of pigment particles or to fine pigments due to the limited milling capability of conventional FIB. In this respect, typical commercial coatings have multiphase pigments ranging from tens of nanometers to tens of micrometers. New dual beam plasma FIBs equipped with EDXS and EBSD can be a good tool for the failure analysis and coating design. Fig. 1 shows the large area milling revealing pigment distribution. The analysed 3D block was $250 \times 100 \times 30 \mu \mathrm{m}^{3}$. A crack at the coating interface at slice number 29 was revealed (Fig. 1b). Coating materials found inside the crack indicated the crack was formed before applying the coating on the substrate which has been subjected to abrasive blast cleaning process. Fig.2 illustrates the automated 3D block preparation method. The sample was on $36^{\circ}$ face of the FEI 3D sample holder respect to the optical axis of the beam. The area of interest (ROI) was identified with the stage tilted to $0^{\circ}$ and coated with $\mathrm{Pt}(200 \mathrm{~nm}$ thick) to prevent beam-tail damage of the block face. The stage was then rotated $180^{\circ}$ and tilted to $-2^{\circ}$ (Fig.2a). The coating interface was parallel to the ion beam in this position. Milling patterns were applied in order to enable the process to run automatically (without human intervention). A 'Rectangle pattern' was placed on the top surface of the coating in order to remove the excess material (marked as ' 2 ' in Fig. 2b). The pattern size was extended to right side in order to clear the way for Pt deposition in following Pt deposition step. A 'Staircase Pattern' was placed on two sides and on bottom side of the ROI at the interface (marked as ' 3 ' and ' 4 ' in Fig.2b) where pattern deep side was at the edge of the ROI. All the patterns were then left to run at high current without intervention. After the pattern milling was finished, the stage was then rotated $180^{\circ}$ and tilted to $16^{\circ}$ (Fig 2c) where normal Pt deposition (marked as ' $\mathrm{a}$ ' in Fig.2b) and automated sequential milling and imaging were performed (Fig.2c-d). In conclusion, the automated block milling procedure proposed face-up milling instead of conventional top-down 3D block milling in order to run milling steps automatically without human intervention. All 4 sides of the block face could be milled without intervention in contrast to the conventional block preparation method that usually requires stage movement during milling steps thereby requiring operator intervention. 


\section{References:}

[1] M. D. Uchic in "Computational Methods for Microstructure-Property”, Ed. S. Ghosh and D. Dimiduk, (Springer, Wright-Patterson) p.31.

[2] S. B. Lyon, R. Bingham, and D.J. Mill, Progress in Organic Coatings 102 (2017), p. 2.

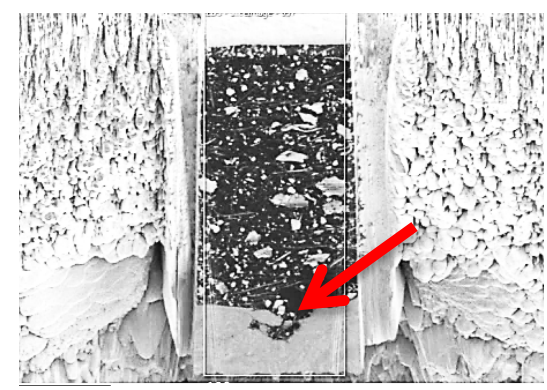

(a)

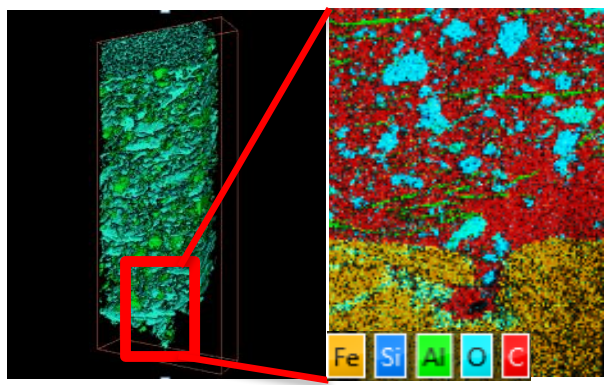

(b)

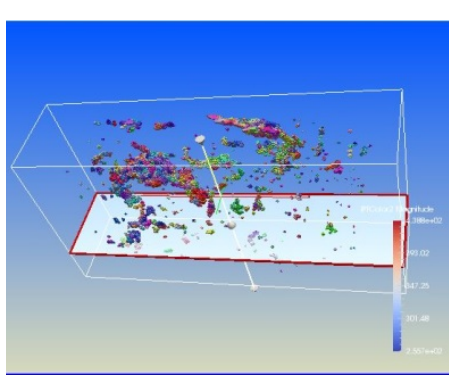

(c)

Figure 1. a) Electron image of slice $29^{\text {th }}$ showing large area of coating cross-section and coating-substrate interface, b) 3D visualization using EDS map for $\mathrm{Al}$ and $\mathrm{SiO}_{2}$ pigments, d) EBSD IPF map of Al pigment.

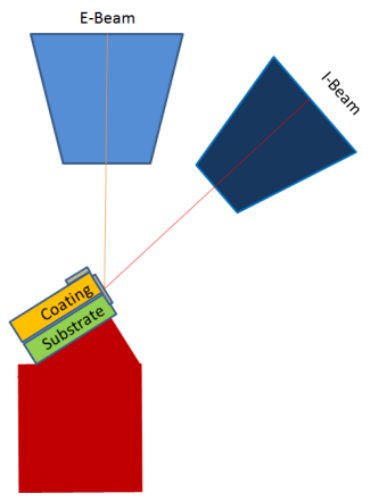

(a)
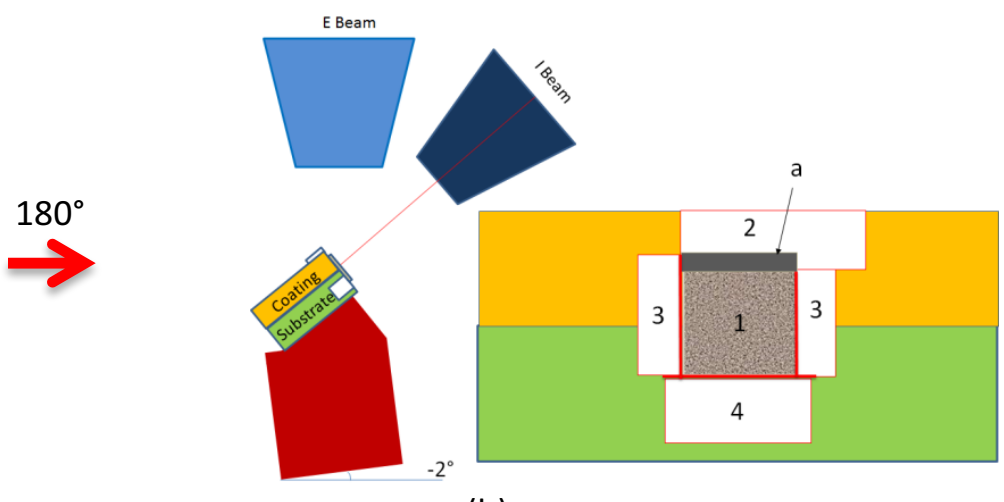

(b)

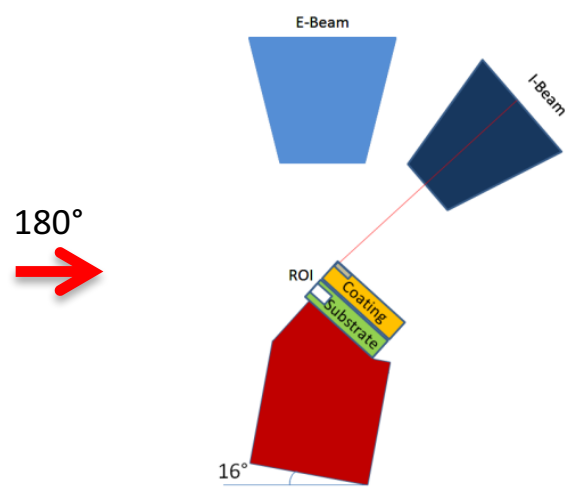

$180^{\circ}$

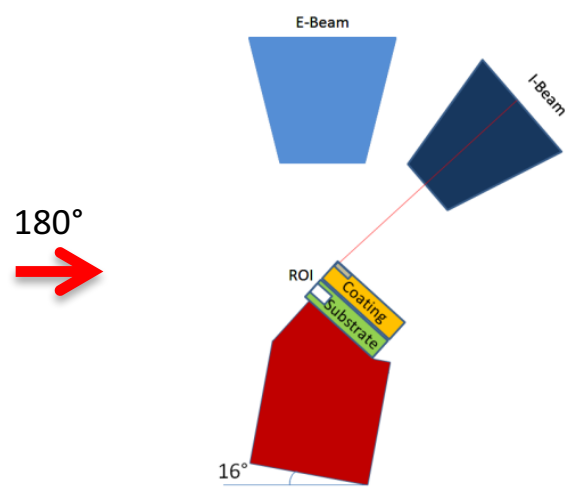

(c)
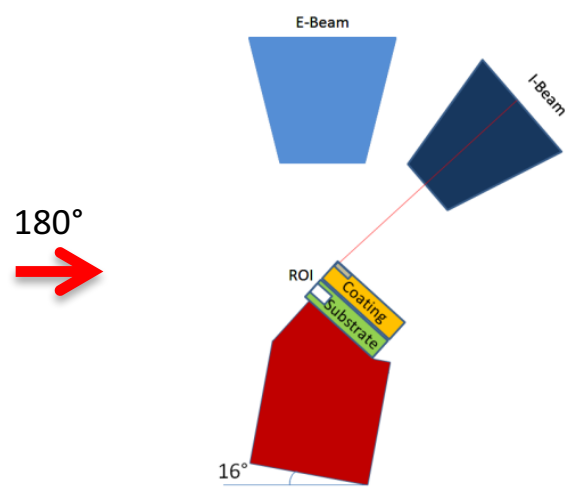

Figure 2. Schematic procedure of automated 3D block preparation by optimization of stage position and milling

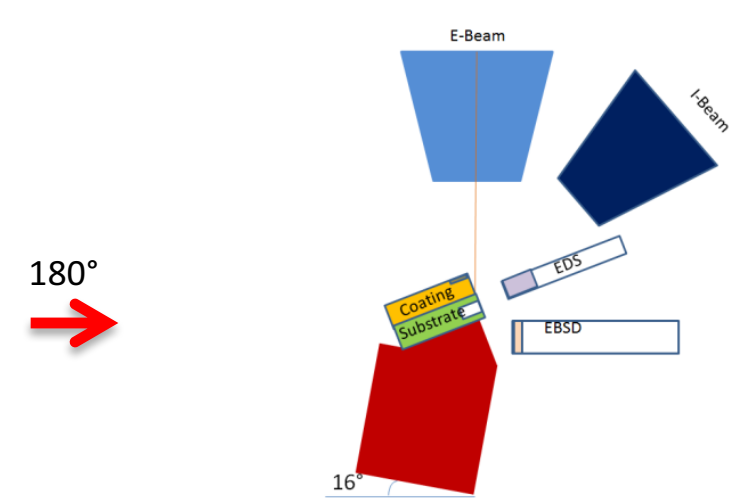

(d) of the coating interface, a) stage at $0^{\circ}$ for ROI and Pt deposition on the block face, b) stage rotated 180 degree and tilted to $-2^{\circ}$ were continues milling was carried out without human intervention, c) stage rotated $180^{\circ}$ again and tilted to $16^{\circ}$ for protective deposition on top of the block, d) stage rotated $180^{\circ}$ for imaging. 